\title{
UCRL 92121
}

PREPRINT

$\left(\begin{array}{c}x \\ x^{2}\end{array}\right.$

CONF-850759--1

A NEW APPROACH TO MULTIPHASE EQUILIBRIA: APPLICATION TO HIGH-PRESSURE PHYSICS PROBLEMS

Francis $H$. Ree

University of California

Lawrence Livermore National Laboratory

Livermore, California $\$ 4550$

This paper was prepared for proceedings of the $X$ th AIRAPT High Pressure Conference on Research in High Pressure Sclence and Technology Amsterdam. The Netherlands July $8-11,1985$

June 1985

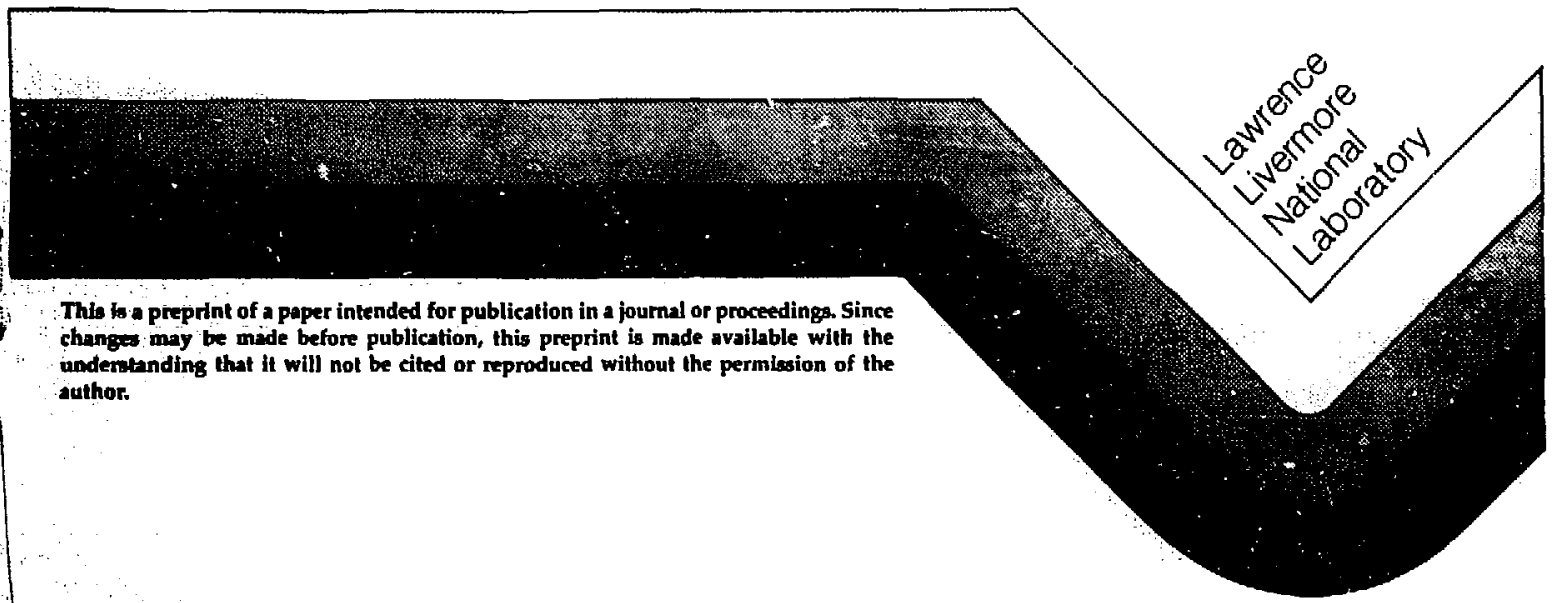




\section{A NEW APPROACH TO MULTIPHAJE EQUILIBRIA: APPLICATION TO HIGH-PRESSURE PHYSICS PROBLEYS \\ Francis H. Ree \\ University of California, Lawrence Livermore National Laboratory \\ Livermore, Callfornta 94550 , U. S. A.}

Abstract

UCRL- -92121

DE85 013820

A multiphase, multicomponent equation-of-state (EOS) model based on first principles of statistical mechanics is described. The model has been used to study fluid-fluid phase sepparations in binary $\left(\mathrm{H}_{2}-\mathrm{He}, \mathrm{Ar}-\mathrm{Ne}, \mathrm{Xe}-\mathrm{He}\right.$, and $\mathrm{N}_{2}-\mathrm{H}_{2} \mathrm{O}$ ) and ternary or more complex systems involying species with $\mathrm{C}, \mathrm{H}$, $N$, and 0 atoms. Results of these calculations and a brief discription on a new theory which can simultaneously describe both solid and fluid EOS properties are given.

Key words: multiphase, multicomponent; fluid-fluld phase separation, equations of state of solid and fluid.

\section{DISCLAMMER}

This report was prepared as an account of work eponsored by an agency of the United States Government. Neither the United States Government nor any agency thereof, nor any of their employees, makes any warranty, eipress or implied, of assumes any legal liability or responsibility for the accuracy, conjiseteness, or usefulness of any information, apparatus, product, or process disclosed, or representr itst its use would not infringe privalely owned rights. Reforence herein to any specific commercial product, process, or service by trade name, trademark, manufacturer, or otherwise does not necessarily constitute or imply its endorsement, recommendation, or favoring by the Unitod States Government or any agency thereof. The views and opinions of authors expressed herein do not necessarily state or reflect these of the United States Government or any agency thereof. 


\section{1 . Model of multiphase chemical equilibrium}

The objective of this paper is to describe and apply a statistical mechanical model of multicomponent and multiphase systems. Necessary ingredients of such a theory are: (a) an efficient method of solving for the concentrations of the molecular spectes, (b) realistic intermolecular potentials, (c) accurate solid and fluid equations of state (EOS), and (d) a reliable mixture model. During the past fifteen years there have been significant advances made in these subjects. As a result, we were able to develop the chemical equflibrium (CHEQ) computer code [1] which mostly makes use of (a) $-(d)$ above.

The CHEQ code evaluates themodynamic properties of a mixture of given chemical species with known atomic composition at fixed pressure (P) and temperature $(i)$. The mixture can be in several so?id and fluid phases. Equilibrium compositions $\left[n_{j}\right]$ of chemical species are calculated by minimizing the Gibbs free energy $G\left(P, T,\left[n_{j}\right\}\right)$ which is, in turn, expressed in terms of the chemical potentials of the constituents. The only link between the CHEQ code and EDS theories occurs through the cherical potentials. The remaining portion of the CHEQ code is concerned with numerically minimizing the free energy by using the extent-of-reaction variable method. This method has been discussed by Prigogine and Defay [2].

The model described above requires EOS expressions for each phase. In the case of fluid phase, we use the Ross theory [3] in which the Helmholtz free energy $A$

$$
\begin{aligned}
A<A_{H S} & +F(n) N k T+(\rho N / 2) \int d r \underset{\sim}{\phi}(r) g_{H S}(r) \\
& +A_{q m}
\end{aligned}
$$


is minfinfzed with respect to the hard-sphere packing fraction $n$.

Expressions for the hard-sphere quantities $A_{H S}, g_{H S}(r)$, and $F(n)$ are given in [3]. The last term, $A_{q m}$, is the first-order wigner-kirkwood quantum correction:

$$
A_{q m}=\frac{N h^{2} \rho}{96 r^{2} m k T} \int d r \nabla^{2} \phi(r) g_{H s}(r)
$$

where $m$ denotes the mass of constituent molecules.

In the discussion to follow, we will use the exponential-six (exp-6) potential,

$$
\begin{array}{r}
\phi(r)=\frac{c}{\alpha-6}\left[6 \exp \left[\alpha\left(1-r / r^{*}\right)\right]\right. \\
\left.-\alpha\left(r^{\star} / r\right)^{6}\right] .
\end{array}
$$

to represent intermolecular potentials. Exp-6 parameters $\left(\varepsilon, r^{*}, a\right)$ for chemical species of interest here are given in [1]. Thermodynamic properties computed from Egs. (1)-(3) have been shown to agree with computer simulations [3] and experimental data $[4,5]$.

The above one-component EOS theory has been extended to mixtures by using an improved van der Waals one-fluid model [6]. In this model the mixture potentials are replaced by an effective exp-6 potential with its parameters expressed in terms of the parameters of constituent species by

$$
\begin{aligned}
\left(r^{*}\right)^{3} & =\sum_{1, j} x_{i} x_{j}\left(r_{i j}^{*}\right)^{3}, \\
c & =\sum_{i, j} x_{i} x_{j} e_{i j}\left(r_{i j}^{*}\right)^{3} /\left(r^{*}\right)^{3} . \\
\alpha & =\sum_{i, j} x_{i} x_{j} \alpha_{i j} \varepsilon_{i j}\left(r_{i j}^{*}\right)^{3} / c\left(r^{*}\right)^{3},
\end{aligned}
$$


where $x_{i}$ denotes the mole fraction of species $i$. The quantum correction, Eq. (2), for mixtures can be accomodated, with in the effective one-compontent framework, by introducing an effective mass $\mathrm{m}$ :

$$
1 / m=\sum_{i, j} x_{i} x_{j}\left(1 / m_{i}\right) \varepsilon_{i j} \cdot r_{i j}^{*} / \Leftrightarrow r^{*}
$$

The accuracy of the effective one-component model has been tested against Honte Carlo (MC) results for a two-compontent mixture of $\mathrm{H}_{2}$ and He [7].

2. A new EOS theory of fluid and solid

Typical calculation of a 10-component system by the CHEQ code takes approximately $10^{3}$ to $10^{4}$ seconds of CRAY computer time per $(P, T)$-point for most potentials. In the case of an exp-6 potential the computing time can be shortened by a factor of about 50 to 100 . Nevertheless, computing time becomes formidable for complex calculation.

With this in mind, we have developed a new perturbation theory [B]. The new approach divides $\phi(r)$ into a reference potential $\phi_{0}(r)$ and a perturbation potential $\phi_{1}(r), 1 . e ., \phi(r)=\phi_{0}(r)+\phi_{7}(r)$ with

$$
\begin{array}{rlrl}
\phi_{0}(r) & =\phi(r)-F(r), & & \text { if } r \leq \lambda, \\
& =0, & & \text { if } r>\lambda, \\
\phi_{1}(r) & =F(r), & & \text { if } r \leq \lambda, \\
& =\phi(r) . & \text { if } r>\lambda,
\end{array}
$$

by introducing a break point $\lambda=\min \left(a_{f c c}, r^{\star}\right)$, where $a_{f c c}$ is the nearest-neighbor distance $\left(2^{1 / 6} / p^{1 / 3}\right)$ of an fec structure. Both 
$\phi_{0}(r)$ and $\phi_{j}(r)$ contain a function $F(r)$ which is chosen to make the perturbation serias converge fast:

The free energy $A_{0}$ of the reference system is replaced by that of hard spheres using the hard-sphere diemeter of the Weeks-Chandler-Añderson (WCA) theory [9]. Note that the present perturbation scheme reduces to the WCA theory if density is less than $\rho\left(r^{\star}\right)^{3}=\sqrt{2}$. At higher densities the range, $\lambda$, of $\phi_{0}(r)$ shrinks with density, which is a desirable feature. Table I gives comparison of exp-6 thermodynamic properties at $k T / c=20$. An advantage of the new theory is that the hard-sphere diameter can be expressed analyticaliy.

It is worthwille to test the EOS theory described above for solids as we 11 . We have obtained encouraging results for Lennard-Jones, exp-6, and inverse nth-power fcc systems [10]. Table I shows comparison of PV/NkT for an exp-6 potential. A complete study will be published in due course.

3. Fluid-fluid phase separation in binary and ternary systems

Experimentäl solubility data offer a reliable basis for fixing unlike-pair interactions in condensed matter. For a simple binary mixture, this can be done by directly evaluating $G$ and soiving for a pair of roots, $x^{\prime}$ and $x^{\prime \prime}(x=m o l e$ fraction of species 1$)$, at which the excess Gibbs free energy of mixing has a common tangent. This procedure has been applied [7], in conjunction with Streett's experimental data of the $\mathrm{H}_{2}-\mathrm{He}$ system [11]. The resulting exp-6 parameters reproduce streett's data at $T \geq 61.5 \mathrm{~K}$. At lower T, higher-order quantum corrections [than Eq. (2)] become important. (Hore recent]y, Schouten et al. [12] extended the experimental critical solubility line to $5 \mathrm{GPa}$. 
An alternative and more general way to compute the solublitty line is to use the CHEQ code. In Fig. I the resulting theoretical solubility lines of the Ar-Ne system are compared with the experimen'ia] data of Streett [13] at subcritical temperatures of argon. Similar comparison on the Xe-He system is given in Fig. 2, using de Swaan Arons and Diepen's data [14]. The calculations are based on 1ike-pair exp-6 parameters derived from the corresponding-states scaling relations [4] and the unlike-pair $c_{i j}$ values from an empirical rule [15]. Since the main purpose of the calculations was to test the CHEQ code, no attempt was made to "fine-tune" the exp-6 parameters. Therefore, it is encouraging to see reasonable agreement between theory and experiment. Near the critical region, however, the theoretical results tend to become "stiffer". Thls unphysical behavior is connected with our use of the free energy expresston, Eq. (1), which becomes nonconvex with. respect to variation of $n_{i}{ }^{\prime} s$. Its use in the CHEQ code can cause a computational problem near the critical region, because an algorithm used to minimize $G$ in the CHEQ code takes advantage of the convexity of $G$.

We next consider the supercritical fluid phase separation in mixtures of polar and nonpolar molecules. Molecules such as $\mathrm{H}_{2} \mathrm{O}$ and $\mathrm{NH}_{3}$ have a strong electrostatic attraction. At high temperature it is possible to include the electrostatic interaction by using

$$
\phi(r, T)=(1+h / T) \phi(r)
$$

where $\phi(r)$ is given by Eq. (3) and the factor $\lambda / T$ represents a spherically averaced electrostatic dipole interaction [1]. For water molecules, for example, $\lambda$ is equal to $996.8 \mathrm{~K}[1]$. 
The experinental critical solubility lines of the $\mathrm{CO}_{2}-\mathrm{H}_{2} \mathrm{O}$ system $[16]$ shows that $\mathrm{H}_{2} \mathrm{O}$ and $\mathrm{CO}_{2}$ molecules are soluble at $\mathrm{T} \geq 550 \times$ and $\mathrm{P} \geq 100 \mathrm{MPa}$. $\mathrm{In}$ contrast, the experimenta $1 \mathrm{~N}_{2}-\mathrm{H}_{2} \mathrm{O}$ data [1] shows 1 imited solubillty $1 \mathrm{n}$ the same $(P, T)$ range. These molecules are major detonation products of condensed explosives. Since the region of interest for explosives ltes above $10 \mathrm{GPa}$ and $1000 \mathrm{~K}$ where experimental data of mixtures are not avallabie, we applied our model to study the $\mathrm{N}_{2}-\mathrm{H}_{2} \mathrm{O}-\mathrm{CO}_{2}$ system. Figure 3 shows the theoretical solubility lines at $0.35 \mathrm{eV}(4062 \mathrm{~K})$. Sensitivity of the solublitity lines to the unlike-pair repulsive narameters and influence of $\mathrm{CO}_{2}$ are indicated in Fig. 3. The most important conclusion from this study is that detonation properties will likely be affected by the fluid-fluid phase separation in Fig. 3 .

4. High-pressure fluid-phase separation in more complex mixtures

We are now in a position to try our model to more complex systems. We first consider PBX-9404, a.t explosive with composition of

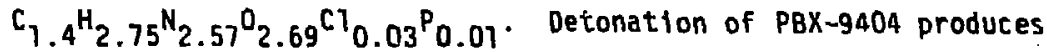
$\mathrm{N}_{2}, \mathrm{CO}_{2}, \mathrm{H}_{2} \mathrm{O}$, and solid $\mathrm{C}$ with minor amounts of $\mathrm{H}_{2}, \mathrm{NH}_{3}, \mathrm{CO}, \mathrm{O}_{2}, \mathrm{CH}_{4}$, and $\mathrm{NO}$ (neglecting species with $P$ and $\mathrm{Cl}$ ). Two sets of calculations are carried out. The first set assumes detonation products to be in two phases, i.e., a gas-phase mixture of the aforementioned nine molecules and a solit phase of carbon (graphite or diamond). The second set is a three-phase calculation, in which a gas phase of $\mathrm{N}_{2}$ and $\mathrm{CO}_{2}$ is added to the first set. The additional phase is introduced to accommodate the flutd-phase separation in the $\mathrm{N}_{2}-\mathrm{H}_{2} \mathrm{O}$ system. See Sec. 3 . 
In Fig. 4 the experimental shock pressure data of PBX-9404 [19,20] are coppared with the two theoretical calculations. We note that the three-phase calculation gives a better agreement with the experimental data. It should be pointed out that the second gas phase does not occur at all pressures and temperatures. It occurs only if its inclusion lowers the Gibbs free energy. In a separate paper [21], we discuss in detail why and how a fluid phase separation affects the detonation properties of PBX-9404.

We next consider two hypothetical systems, composed of the same chemical species as in the PBX-9404 case. One of them has $C / H, N / H$, and $0 / H$ ratios equal to the solar abundance ratios [22] and the second with 100 times larger values. Calculations are done at $P=10 \mathrm{GPa}$ and $T=2200 \mathrm{~K}$ which approximately represents the condition at an interior point of Uranus or Neptune. Fluid-fluid phase separation is allowed for the nine species. Results summarized in Table II show that the fluid phase separation does not occur in the first case. This probably is not true for the outer planets, since other species (e.g., helium, neglected in the present calculations) or concentration fluctuations (present in the planetary interiors) will favor fluid-phase separation. The second calculatisil which is probably more realistic predicts that $\mathrm{H}_{2} \mathrm{O}$ and $\mathrm{NH}_{3}$ molecules undergo a fluid-phase separation. This can explain why one expects to find the "ice" and the hydrogen-rich layers, as assumed in the current models of the outer planets [23]. The predicted phase separation could also explain the observed depletion of $\mathrm{N} / \mathrm{H}$ and $\mathrm{O} / \mathrm{H}$ compared with the solar values in atmospheres of Uranus and Neptune [24]. Our model predicts that $\mathrm{CH}_{4}$ molecules prefer to coextst with $\mathrm{H}_{2} \mathrm{O}$ and $\mathrm{NH}_{3}$ rather than with $\mathrm{H}_{2}$. This prediction may conflict with the abserved (2 to 20 times) enhancements of $\mathrm{C} / \mathrm{H}$ [25] in the planetary atmospheres. For Jupiter and Saturn, the difficulty could be resolved if the metallic hydrogen existing 
deep inside the planets is only slightiy soluble with carbon. The calculation shows no diamond formation. Further study is needed to substantlate an interesting proposal by Ross [26] about possibifity of diamond in uranis and Neptune.

\section{Concluding remarks}

The area of multicomponent and multiphase physics and chemistry has many applications but theoretical progress in this field has been slow. In this paper we have described an nonempirical approach to multiphase, chemical equilibria. The model has been applied to several mixture systems. We have discussed possible improvements of the CHEQ code, related to a unified soitid and fluid EOS theory. The CHEQ model also needs to be improved to properiy describe the behavicr near the critical region of fluid-phase separation. In this regard, it is important to have experimental solubility data of the $\mathrm{N}_{2}-\mathrm{H}_{2} \mathrm{O}$ system at pressures above $10 \mathrm{GPa}$.

\section{Acknowledgments}

I would like to thank W. Hubbard, M. Ross, and M. van Thiel for their pertinent suggestiins related to this work.

This work was performed under the auspices of the U. S. Department of Energy by Lawrence Livermore National Laboratory under contract W-7405-Eng-48. 


\section{P.eferences}

[1] F. H. Ree, J, Chem. Phys, $8 i$ (1984) 1251.

[2] I. Prigogine and R. Defay, Chemical Thermodynamics, translated by D. H. Everett (Longman Green, London, 1954), Chapt. 29.

[3] M. Ross. J. Chem. Phys. 71 (1979) 1567.

[4] M. Ross and F. H. Ree, J. Chem. Phys. 73 (1980) 6145.

[5] W. J. Nellis in Shock Waves in Condensed Matter-1983, J. R. Asay, R. A. Graham, and G. K. Straub, eds. (North-Holland, Amsterdam, 1984), p. 31; and references quoted therin.

[6] F. H. Ree, J. Chem. Phys. 78 (1983) 409.

[7] F. H. Ree, J. Phys. Chem. 87 (1983) 2846.

[8] H. S. Kang, C. S. Lee, T. Ree, and F. H. Ree, J. Chem. Phys. 82 (1985) 414.

[9] 3. D. Weeks, D. Chandler, and H. C. Anderson, J. Chem. Phys. 54 (1971) 5237.

[10] H. S. Kang, T. Ree, and F. H. Ree, preprint.

[11] W. B. Street, Astrophys. J. 186 (1973) 1107.

[12] J. A. Schouten, i. C. van den Bergh, and N. J. Trappeniers, Chem. Phys. Letters 114 (1985) 401.

[13] W. B. Streett, J. Chem. Phys. 46 (1967) 3282.

[14] J. de Swaan Arons and G. A. M. Diepen, J. Chem. Phys. 44 (7966) 2322.

[15] M. J. Hiza and A. G. Duncan, AIChE J. 16 (1970) 733.

[16] K: Tödheide and E. U. Franck, Zeftschrift für Physikalische Chemie Neue Folge 37 (1963) 387.

[17] V. M. Prokhorov and D. S. Tsiklis, Russian J. Phys. Chein. 44 (1980) 1173.

[18] D. S. Tsik]is, Russian J. Phys. Chem. 50 (1976) Bas. 
[19] E. L. Lee, H. van ThieT, L. G. Green, and A. Mitche11, in [5], P. 677, L G. Green, E. L. Lee, A. Mitche11, and C. Tarver, in Proc. Bth Symposfun (International) on Detonation (to be published).

[20] J. H. Kineke, Jr. and C. E. West, in Proc : 5th Symposium (International) on Detonation, ACR-184, ONR 0851-0057 (U.S. Naval Ord. Lab., Pasadena, 1970), p. 553.

[21] F. H. Ree, a preprint.

[22] E. Anders and M. Ebihara, Geochim. Cr.smochim. Acta 46 (1982) 2362.

[23] W. B. Hubbard and J. J. MacFarlane, J. Geophys. Res. 85 (1980) 225; 0. J. Stevenson, in Mat. Res. Soc. Symp. Vol. 22, Part III (North-Holland, Amsterdam 1984) P. 357; M. Podolak, in Uranus and the Outer Planets, G. Hunt, ed. (Cambridge Univ.. 1982) p. 93.

[24] S. Gulkis, M. A. Janssen, and E. T. 01sen, Icarus 34 (1977) 10.

[25] D. Gautier and T. Owen, Nature 304 (1983) 691.

[26] M. Ross, Nature 292 (1981) 435. 
Table 1 Comparison of PV/NkT of exact Honte Carlo calculations with the new perturbation theory for the exp-6 system at $\mathrm{kT} / \mathrm{c}=20$.

\begin{tabular}{llcr}
\hline & & \multicolumn{2}{c}{$P V /(N k T)$} \\
\hline Fluid & $p\left(r^{*}\right)^{3} / \sqrt{2}$ & Exact $^{\mathrm{a}}$ & Theory $^{\mathrm{b}}$ \\
& 0.9 & 3.27 & 3.27 \\
& 1.0 & 3.87 & 3.80 \\
& 1.5 & 8.07 & 8.04 \\
& 2.05 & 16.58 & 16.65 \\
Sol1d & 2.308 & & 20.19 \\
& 2.7 & 30.66 & 30.84 \\
\hline
\end{tabular}

\footnotetext{
a References 3, 8, and 11 .

b References 8 and 11 .
}

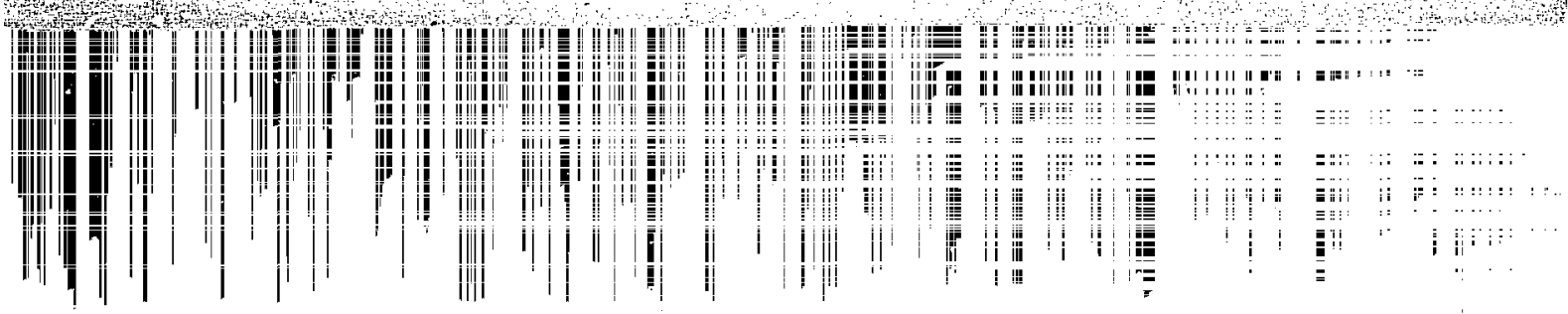


Table II. Chemical compositions in multiphase equilibrla at $2200 \% \mathrm{~K}$ and 10 GPa (corresponding to an intertor position a of itranus and Neptune).

\begin{tabular}{|c|c|c|c|c|c|}
\hline & \multicolumn{2}{|c|}{ Solar Compositionb } & \multicolumn{3}{|c|}{$100 \times$ Solar $(C, N, 0) c$} \\
\hline & Solid & $\begin{array}{l}\text { Fluid } A=\text { Fluid } B \\
\text { (mole } x \text { ) }\end{array}$ & Soltd & $\begin{array}{l}\text { Fluid } A \\
\text { (mole } x \text { ) }\end{array}$ & $\begin{array}{l}\text { Fluid } B \\
\text { (mole } x)\end{array}$ \\
\hline $\mathrm{H}_{2}$ & & 99.7467 & & 93.5986 & 4.9361 \\
\hline $\mathrm{H}_{2} \mathrm{O}$ & & 0.1496 & & 0.1391 & 74.5971 \\
\hline $\mathrm{Ni}_{3}$ & & 0.0119 & & 0.0052 & 9.0124 \\
\hline $\mathrm{CH}_{4}$ & & 0.0888 & & 6.2570 & 11.4543 \\
\hline $\mathrm{CO}$ & & 0.0000 & & 0.0001 & 0.0001 \\
\hline $\mathrm{CO}_{2}$ & & 0.0000 & & 0.0000 & 0.0001 \\
\hline $\mathrm{N}_{2}$ & & 0.0030 & & 0.0000 & 0.0000 \\
\hline NO & & 0.0000 & & 0.0000 & 0.0000 \\
\hline $\mathrm{O}_{2}$ & & 0.0000 & & 0.0000 & 0.0000 \\
\hline Diamond & 0 & -- & 0 & - & $\cdots$ \\
\hline
\end{tabular}

a W. Hubbard, private communication.

b Input compositions: $\left(\mathrm{H}_{2}, \mathrm{H}_{2} \mathrm{O}, \mathrm{CH}_{4}, \mathrm{NH}_{3}\right)=(1,0.0015,0.00089,0.00018)$ moles.

c Input compositions: $\left(\mathrm{H}_{2}, \mathrm{H}_{2} \mathrm{O}, \mathrm{CH}_{4}, \mathrm{NH}_{3}\right)=(1,0.15,0.089,0.078)$ moles. 


\section{FIGURE CAPYIONS}

Fig. 1 Liquid-gas solubility lines of Ar-Ne mixture. Comparison between the present result and the experimental data [i3].

Fig. 2 Gas-gas solubility lines of Xe-He mixture. Comparison between the present work (= dash-dot 1 ines) and the experimental data (=solid lines) [14].

Fig. 3 Theoretical solubility lines of $\mathrm{N}_{2}-\mathrm{H}_{2} \mathrm{O}$ system with and without 22.6 molex $\mathrm{CO}_{2}$ at $0.35 \mathrm{eV}(4062 \mathrm{~K})$. Effect of changing an exp-6 potential parameter, $r^{*}$, is also examined.

Fig. 4 Shock pressure vs compression of $\mathrm{PBX}-9404\left(V_{0}=i n i t i a l\right.$ volume $=$ $0.543 \mathrm{~cm}^{3} / \mathrm{g}$ ). Comparison between the theoretical and the experimental results. Experimental data are from Kineke and West [20] and the Lawrence Livermore National Laboratory (LLNL) data by Lee and Green et al. [19]. The CHEQ-2 phase result uses a model of a fluid-phase mixture plus a solid carbon phase (graphite or diamond). The CHEQ 3-phase result is based on two fluid phases (i.e.. $\mathrm{N}_{2}$-rich and $\mathrm{N}_{2}$-poor mixtures) and a solid carbon phase. 


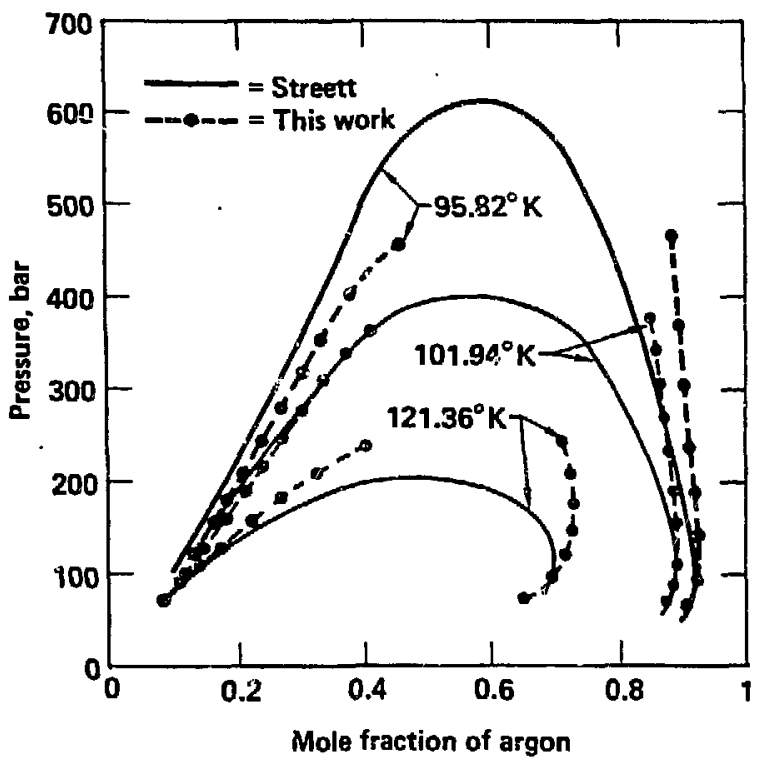

i . 1 


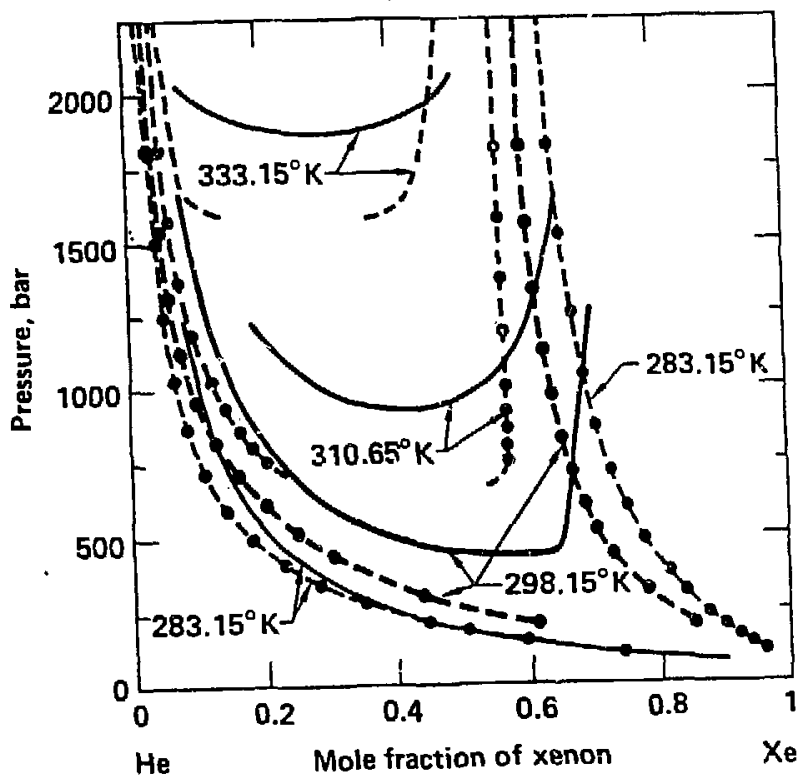

Fig. 2 


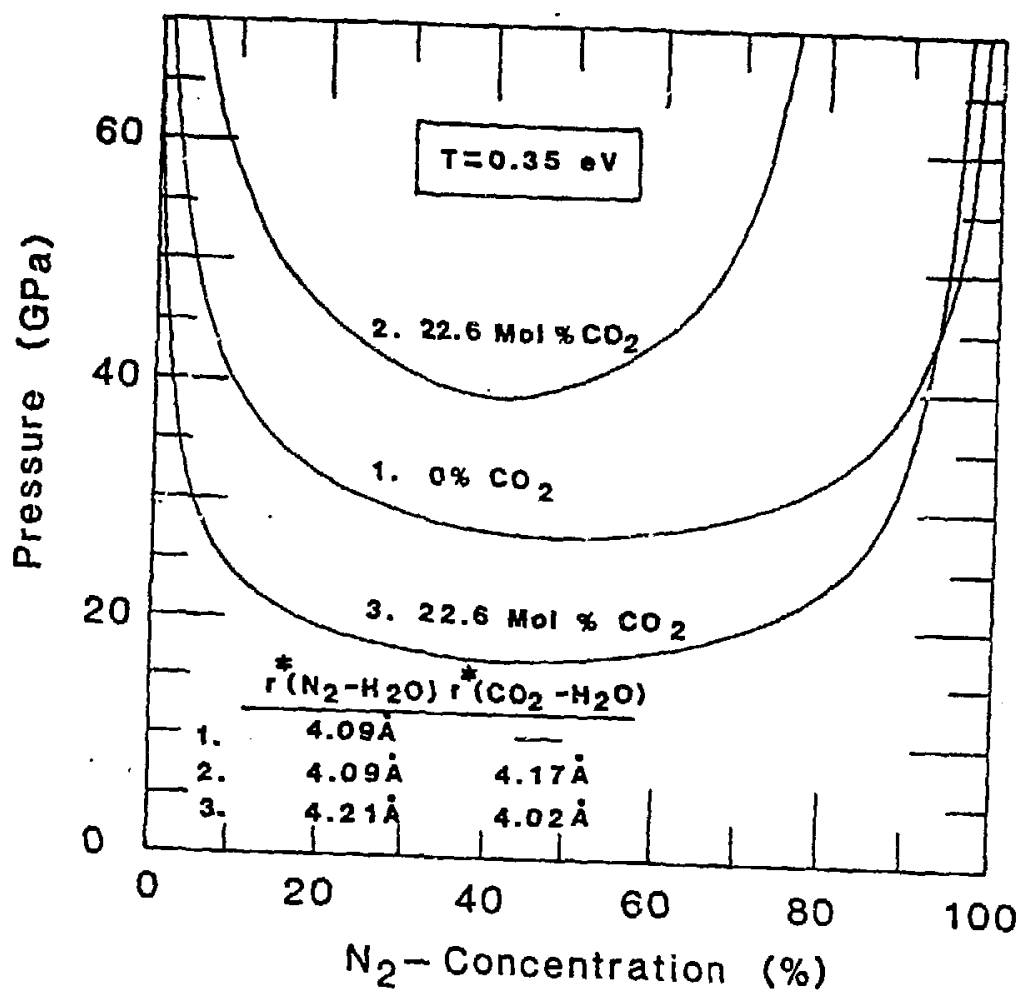

Fig. 3 


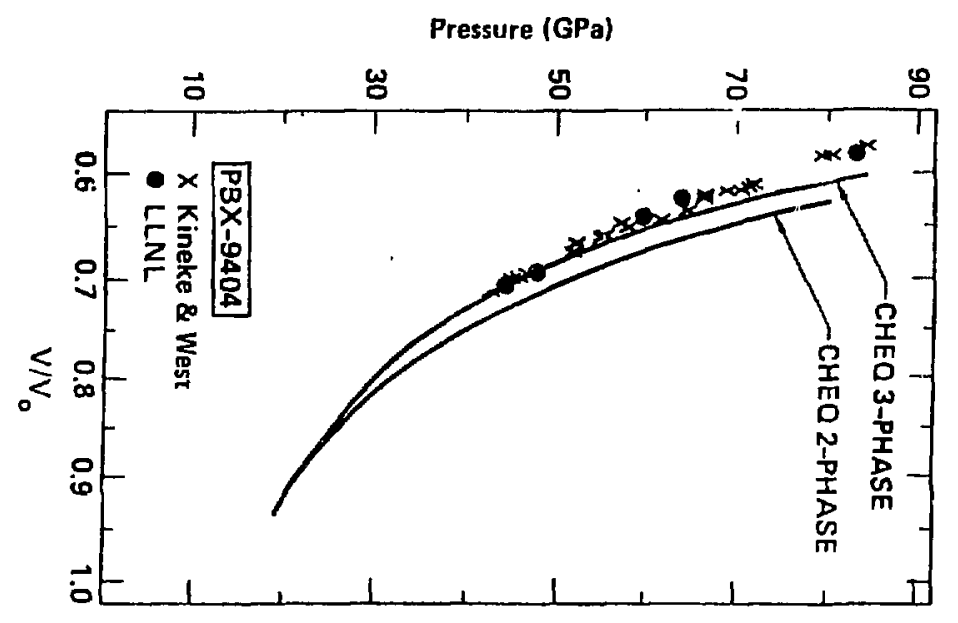

مُ 